\title{
Canadian Association of Gastroenterology position statement: Hip fracture and proton pump inhibitor therapy - a 2013 update
}

\author{
Paul Moayyedi BSc MBChB PhD MPH FRCP FRCPC AGAF FACG, Yuhong Yuan MSc MD PhD, \\ Grigorios Leontiadis MD PhD; on behalf of the CAG Clinical Affairs
}

$\mathrm{H}_{\mathrm{r}}^{\mathrm{c}}$ ealth Canada recently provided an information update on proton pump inhibitor (PPI) therapy and risk of fracture in April 2013 (1) stating "Several scientific studies suggest that PPI therapy may be associated with a small increased risk for fractures of the hip, wrist, or spine related to osteoporosis, a disease resulting in the weakening of bones. The risk of fracture was higher in patients who received multiple daily doses of PPIs and therapy for a year or longer. Additional risk factors for osteoporosis, such as age, gender and the presence of other health conditions, may also contribute to the increased risk of fractures. At Health Canada's request, manufacturers of all PPIs marketed in Canada have updated the drug labels for their products to include information on this risk."

The Canadian Association of Gastroenterology (CAG) provided a position statement on PPI therapy and risk of hip fracture in 2008 (2) and we have updated this in light of the recent Health Canada statement. Large administrative databases are a useful tool to assess possible benefit or harms of health care interventions; however, given that billions of associations can be measured with these databases, highly statistically significant findings will inevitably occur by chance. Added to this problem is that any association may simply be due to confounding factors and not due to the health care intervention causing the disease (eg, a database study may find that steroid inhaler therapy increases the risk of lung cancer but this may simply be due to smokers being more likely to have lung disease [and be given steroid inhalers] and smoking causes lung cancer). Associations between health care interventions and risk of harm are, therefore, being reported almost every week and it is, therefore, very difficult for the clinician to know what associations are likely to be causal and what are likely to be spurious. There is no simple answer to this problem because epidemiological data can never prove or disprove a hypothesis. Hill (3) described nine factors that make an association more likely to be causal. We have previously evaluated the evidence for PPI therapy and risk of fracture according to the most important of these factors, namely, strength of the association, biological plausibility, specificity, consistency of the association and evidence of a dose response relationship (4). We have conducted an updated systematic review evaluating PPI therapy and risk of fracture that will be submitted to a peer reviewed journal and have used these data to assess the CAG's position on the use of PPI therapy and risk of fracture.

\section{STRENGTH OF THE ASSOCIATION}

There has been a wealth of data published since the 2008 CAG position statement on PPI therapy and hip fracture risk. Our systematic review identified 13 case control studies (5-17) evaluating 1,101,595 participants. PPI use was associated with fracture with an odds ratio $(\mathrm{OR})=1.21$ (95\% confidence interval $[\mathrm{CI}] 1.07$ to 1.38$)$. There were also 12 cohort studies (18-29) evaluating 834,442 participants over $3,712,891$ patient-years of follow up. Overall, these cohort studies suggested PPI therapy was associated with an increased risk of fracture (relative risk $[R R]=1.30 ; 95 \% \mathrm{CI}=1.13$ to 1.49 ). Overall, the data therefore suggest that PPI therapy may increase the risk of fracture, although the effect is very modest and any association may be due to confounding factors. Studies usually did adjust for some confounding factors but data available from databases is limited and residual confounding cannot be excluded.

\section{BIOLOGICAL PLAUSIBILITY}

The association between PPI therapy and fracture risk would be strengthened if a biologically plausible mechanism could explain the association. The original article that highlighted concerns regarding acid suppression and fracture (6) suggested this could be due to PPI therapy reducing the absorption of calcium. In our systematic review, there were four studies $(18,20,22,27)$ that also assessed the impact of PPI therapy on bone mineral density involving 178,686 subjects; none of these studies found any significant association between PPI therapy and bone mineral density (BMD), with PPI users having very similar BMD to non-users. An additional Canadian study (30) involving 7720 participants also found no association between PPI therapy and the presence of osteoporosis or with BMD loss over time. The association between PPI therapy and fracture, therefore, does not have a plausible biological explanation with current data.

\section{EVIDENCE OF A DOSE-RESPONSE RELATIONSHIP}

An association is more likely to be causal if more of the risk factor leads to a higher risk of disease. There were three case control studies $(9,12,16)$ that evaluated a dose response in terms of patients taking $<1$ defined daily dose (DDD), 1 DDD, and $>1$ DDD. There was some evidence that moving from $<1$ DDD to PPI therapy once per day was associated with an increased risk (OR 1.14 versus 1.31 ) but little evidence that increasing to $>1$ DDD had any increased risk $(O R=1.40)$ with no statistically significant $(\mathrm{p}=0.51)$ difference between the $\mathrm{OR}$ for subjects taking 1 DDD and those taking higher doses. This was supported by one cohort study (19) that also showed no dose response for PPI therapy.

Another approach for dose response is to evaluate duration of therapy. This was more difficult to assess because studies used slightly different cut-off definitions but there was no significant impact of duration of PPI therapy in four case controls studies $(6,7,9,12$ ) (OR for $<1$ year of use $=1.25$, OR for 1.5 years $=1.32$, OR for $>5$ years $=$ 1.31). There was also no significant impact of duration of PPI therapy in three cohort studies $(19,22,24)(\mathrm{RR}$ for $<1$ year of use $=1.19,1$ to 5 years $=1.20,>5$ years $=1.21)$. There is, therefore, little evidence to support the Health Canada statement that the risk of fracture with PPI therapy increased with multiple doses and longer duration of therapy when all data are evaluated.

\section{SPECIFICITY OF THE ASSOCIATION}

If PPI therapy was the only drug therapy that increased the risk of fracture, then this would strengthen the hypothesis that the association was causal. However, there are numerous drugs that have been associated

The CAG is proud to acknowledge its Benefactor Corporate Sponsors:

AbbVie Corporation

Olympus Canada Inc

Pentax Canada Inc

Janssen Inc

Takeda Canada Inc 
with fracture. Yang et al (6) found antipsychotics, anti-Parkinsonian, and antiseizure drugs were all associated with increased risk of hip fracture. Attention has also focused on the risk of thyroxine replacement and fracture (31), and warfarin has also been implicated (32). Drugs with diverse modes of action are, therefore, all associated with increased risk of fracture and not of all of these have clear mechanisms by which they would exert effects on bone metabolism. This raises the possibility that the association between PPI therapy and fracture risk is spurious and relates to ill patients on a number of medications (including PPI therapy) are at increased risk of experiencing fractures.

\section{CONSISTENCY OF THE DATA}

An association is more likely to be causal if different investigators, in varying populations using different methodologies obtain similar results. This is not the case with PPI therapy and fracture. In our systematic review, 6 case control studies were negative and 7 were positive, and this is reflected in the statistics, which suggest $94 \%$ of the variation in the data is not due to chance. We have explored reasons for heterogeneity and this remains unexplained. Three of the cohort studies were negative and 9 were positive and, again, $88 \%$ of the variation in the data was not explained by chance. We could not identify any factors that explained variations in study results.

\section{WHAT ARE THE RISKS OF FRACTURE WITH PPI THERAPY?}

There is little to support the hypothesis that the association between PPI therapy and risk of fracture is causal. Even if we assume the association is causal, the risk to patients is minimal. Using the OR taken from the meta-analysis of case control studies and a risk calculator developed by WHO (33), approximately 2000 Canadians (we used a 50 -year-old Canadian woman with normal bone density as a baseline) would need to be given PPI therapy to cause one additional fracture in a given year. Of course, the number needed to harm falls as the risk of fracture rises; however, it is important to emphasize that three cohort studies $(19,23,27)$ evaluating high-risk cohorts of patients taking bisphosphonates found no increased risk of fracture in those taking PPI therapy $(\mathrm{RR}$ fracture $=0.89 ; 95 \% \mathrm{CI}=0.67$ to 1.17 ).

The data from this systematic review can also be pooled to assess the proportion of fractures in these cohorts that are attributable to PPI therapy. The population-attributable fraction is calculated to be approximately $1 \%$. In other words, if PPI use was stopped in the community, this would only reduce the fractures in the community by approximately $1 \%$. This seems an extremely modest impact on fracture rates, particularly when the association may be spurious and suggests that we should not be overly concerned regarding PPI therapy in public health terms.

\section{CONCLUSIONS}

There have been numerous studies investigating the risk of fracture with PPI therapy since the CAG position statement in 2008. These data, however, do not change the conclusions of the original position statement. Current data would not support particular care in prescribing PPI therapy due to concerns about risk of fracture. The risk is extremely modest and there is no persuasive evidence that even this risk is causal and the association could be spurious. As with all medications, PPIs should only be given when there are clear indications that the benefit of therapy outweighs the risk.

\section{REFERENCES}

1. http://www.healthycanadians.gc.ca/recall-alert-rappel-avis/ hc-sc/2013/26523a-eng.php (Accessed July 7, 2013).

2. http://www.cag-acg.org/uploads/position/cag_position_ppi_hip_ fracture.pdf (Accessed July 7, 2013).

3. Hill AB. Environment and disease: Association or causation? Proc R Soc Med 1965;58:295-300.

4. Moayyedi P, Cranney A. Hip fracture and proton pump inhibitor therapy: balancing the evidence for benefit and harm. Am J Gastroenterol 2008;103:2428-31.

5. Vestergaard P, Rejnmark L, Mosekilde L. Proton pump inhibitors, histamine $\mathrm{H} 2$ receptor antagonists, and other antacid medications and the risk of fracture. Calcif Tissue Int 2006;79:76-83.

6. Yang YX, Lewis JD, Epstein S, Metz DC. Long-term proton pump inhibitor therapy and risk of hip fracture. JAMA 2006;296:2947-53.

7. Targownik LE, Lix LM, Metge CJ, Prior HJ, Leung S, Leslie WD. Use of proton pump inhibitors and risk of osteoporosis-related fractures. CMAJ 2008;179:319-26.

8. Kaye JA, Jick H. Proton pump inhibitor use and risk of hip fractures in patients without major risk factors. Pharmacotherapy 2008;28:951-9.

9. Corley DA, Kubo A, Zhao W, Quesenberry C. Proton pump inhibitors and histamine-2 receptor antagonists are associated with hip fractures among at-risk patients. Gastroenterology 2010;139:93-101.

10. Chiu HF, Huang YW, Chang CC, Yang CY. Use of proton pump inhibitors increased the risk of hip fracture: A population-based case-control study. Pharmacoepidemiol Drug Saf 2010;19:1131-6.

11. Yong MK, Elliott JH, Woolley IJ, Hoy JF. Low CD4 count is associated with an increased risk of fragility fracture in HIV-infected patients. J Acquir Immune Def Synd 2011;57:205-10.

12. Pouwels S, Lalmohamed A, Souverein P, et al. Use of proton pump inhibitors and risk of hip/femur fracture: A population-based casecontrol study. Osteoporos Int 2011;22:903-10.

13. Turner MR, Camacho X, Fischer HD, et al. Levothyroxine dose and risk of fractures in older adults: nested case-control study. BMJ 2011;342:d2238.

14. Mundy LM, Youk AO, McComsey GA, Bowlin SJ. Overall benefit of antiretroviral treatment on the risk of fracture in HIV: Nested case-control analysis in a health-insured population. AIDS (London, England) 2012;26:1073-82.

15. Mazziotti G, Baracca M, Doga M, Porcelli T, Vescovi PP, Giustina A. Prevalence of thoracic vertebral fractures in hospitalized elderly patients with heart failure. Eur J Endocrinol 2012;167:865-72.

16. Reyes C, Formiga F, Coderch M, et al. Use of proton pump inhibitors and risk of fragility hip fracture in a Mediterranean region. Bone 2013;52:557-61.

17. Chiang CH, Liu CJ, Chen PJ, et al. Hip fracture and risk of acute myocardial infarction: A nationwide study. J Bone Miner Res 2013;28:404-11.

18. Yu EW, Blackwell T, Ensrud KE, et al. Acid-suppressive medications and risk of bone loss and fracture in older adults. Calcif Tissue Int 2008;83:251-9.

19. de Vries F, Cooper AL, Cockle SM, van Staa TP, Cooper C. Fracture risk in patients receiving acid-suppressant medication alone and in combination with bisphosphonates. Osteopor Int 2009;20:1989-98.

20. Roux C, Briot K, Gossec L, et al. Increase in vertebral fracture risk in postmenopausal women using omeprazole. Calcif Tissue Int 2009;84:13-9.

21. Feldstein AC, Weycker D, Nichols GA, et al. Effectiveness of bisphosphonate therapy in a community setting. Bone 2009;44:153-9.

22. Gray SL, LaCroix AZ, Larson J, et al. Proton pump inhibitor use, hip fracture, and change in bone mineral density in postmenopausal women: Results from the Women's Health Initiative. Arch Intern Med 2010;170:765-71.

23. Abrahamsen B, Eiken P, Eastell R. Proton pump inhibitor use and the antifracture efficacy of alendronate. Arch Intern Med 2011:171:998-1004.

24. Khalili H, Huang ES, Jacobson BC, Camargo CA Jr, Feskanich D, Chan AT. Use of proton pump inhibitors and risk of hip fracture in relation to dietary and lifestyle factors: A prospective cohort study. BMJ 2012;344:e372.

25. Mello M, Weideman RA, Little BB, Weideman MW, Cryer B, Brown GR. Proton pump inhibitors increase the incidence of bone fractures in hepatitis C patients. Dig Dis Sci 2012;57:2416-22.

26. Munson JC, Wahl PM, Daniel G, Kimmel SE, Hennessy S. Factors associated with the initiation of proton pump inhibitors in corticosteroid users. Pharmacoepidemiol Drug Safe 2012;21:366-74.

27. Roux C, Goldstein JL, Zhou X, Klemes A, Lindsay R. Vertebral fracture efficacy during risedronate therapy in patients using proton pump inhibitors. Osteoporos Int 2012;23:277-84. 
28. Fraser LA, Leslie WD, Targownik LE, Papaioannou A, Adachi JD. The effect of proton pump inhibitors on fracture risk: Report from the Canadian Multicenter Osteoporosis Study. Osteoporos Int 2013;24:1161-8.

29. Womack JA, Goulet JL, Gibert C, et al. Increased risk of fragility fractures among HIV infected compared to uninfected male veterans. PloS One 2011;6:e17217.

30. Targownik LE, Lix LM, Leung S, Leslie WD. Proton pump inhibitor use is not associated with osteoporosis or accelerated bone mineral density loss. Gastroenterology 2010;138:896-904.
31. Turner MR, Camacho X, Fischer HD, et al. Levothyroxine dose and risk of fractures in older adults: Nested case-control study. BMJ 2011;342:d2238.

32. Gage BF, Birman-Deych E, Radfor MJ, Nilasena DS, Binder EF. Risk of osteoporotic fracture in elderly patients taking warfarin: Results from the National Registry of Atrial Fibrillation 2. Arch Intern Med 2006;166:241-6.

33. http://www.shef.ac.uk/FRAX/ (Accessed July 7, 2013). 


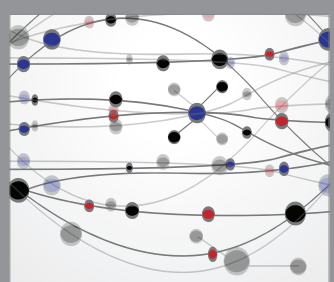

The Scientific World Journal
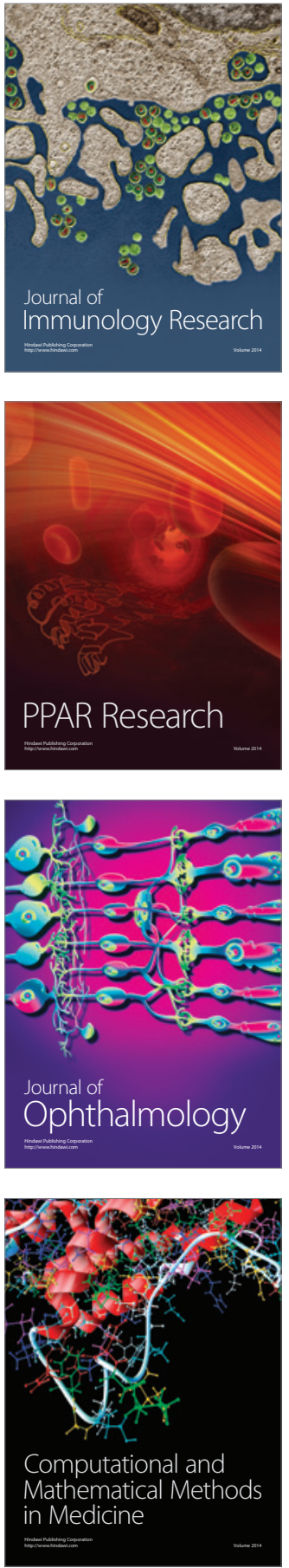

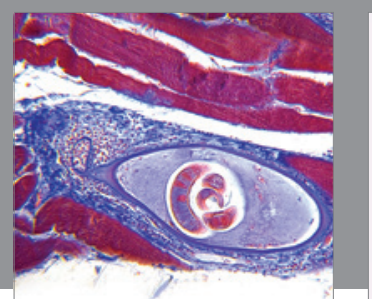

Gastroenterology Research and Practice

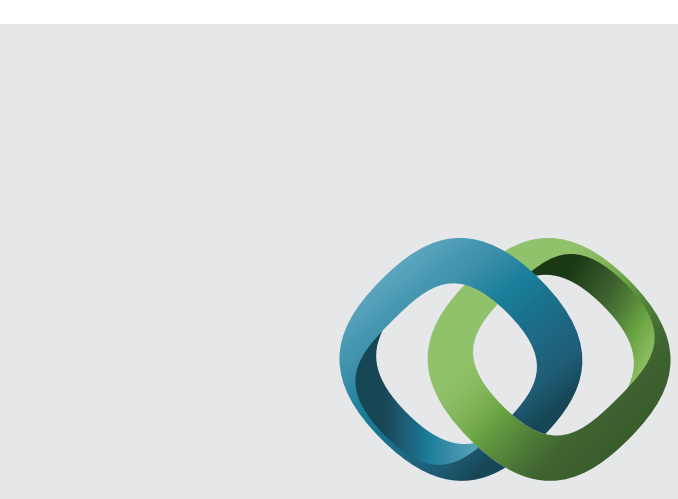

\section{Hindawi}

Submit your manuscripts at

http://www.hindawi.com
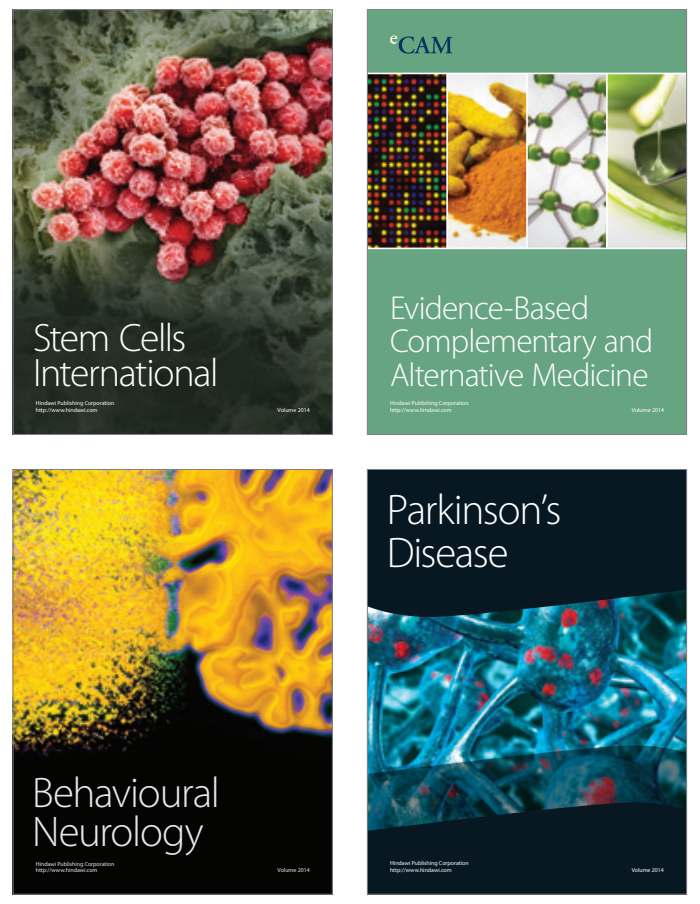
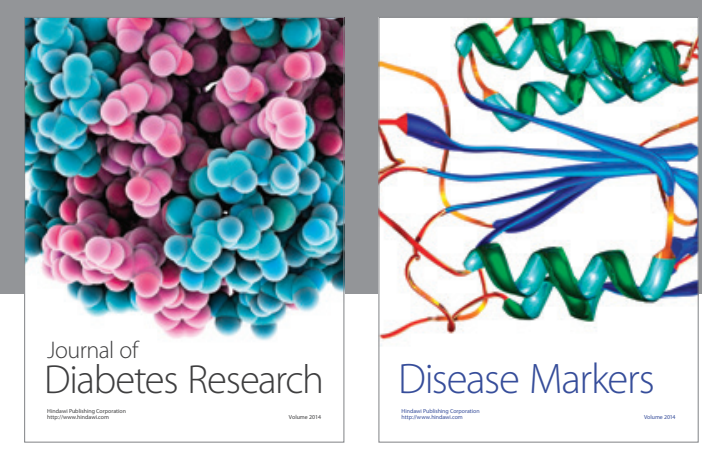

Disease Markers
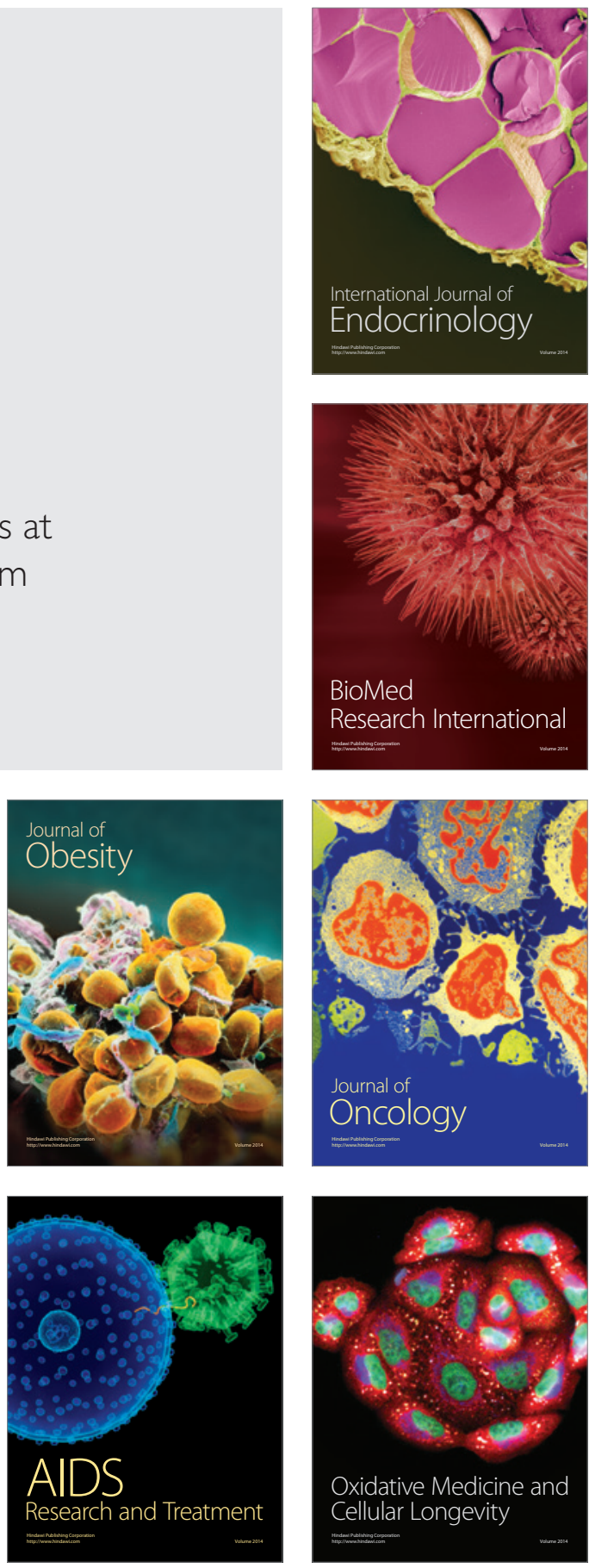